\title{
Corporate Social Responsibility (CSR) Management and Marketing Communication: Research Streams and Themes
}

\begin{abstract}
This article maps the rapidly growing body of research in the field of corporate social responsibility (CSR) management and marketing communication, the focus being on research streams and themes. It evaluates this research from a corporate communication perspective. First, the article examines the concept of CSR communication. A typology of a number of possible domains for CSR communication research is developed, based on the way the different studies conceptualize CSR. Second, the article reviews the concepts of strategic and operative CSR communication which have been adopted widely within the CSR communication literature, relating these to research streams within management and marketing/public relations. Being framed within a corporate communication perspective, the review answers the call for CSR communication research to develop and substantiate outcomes that may better explain or inform CSR communication strategies and practices. A number of categories of outcomes are found within existing empirical studies, and an agenda for building upon this evidence is advanced to allow greater consistency and mutual understanding among CSR communication researchers.
\end{abstract}

\section{Introduction}

Over the last decade, CSR management and marketing communication research has evolved from a small-scale activity in a limited number of industrialized countries to a major global industry (e.g. Global Leaders 2010; Bendell 2011). To judge from the increasing number of websites on CSR, annual or social and environmental reports, codes of conduct or ethics, corporate advertisements on CSR, social partnerships etc., CSR management and marketing communication is clearly understood as a new sub-field within corporate communication (Cornelissen 2011; Pollach et al. 2011), and is therefore considered a commercial investment. On the research side, the growth of CSR management and marketing communication has been accompanied by a number of studies, examining its various practical and theoretical aspects. While this paper is framed within a corporate communication perspective (Van Riel 1995; Cornelissen 2011), allowing us to synthesize the means by which CSR communication activities can add value for stakeholders, other perspectives also contribute insights within the field of CSR communication, e.g. the co-creation perspective on CSR, which is a perspective still in embryo (Crane 2011).

There have been some reviews within specific sub-fields of CSR and CSR communicationrelated literature, e.g. a review of marketing research and CSR from 1958-2008 (Chabowski et al. 2011). The review by Chabowski et al. is based on citations in sustainability-focused articles from selected journals over a period of 51 years, and points out five critical sustainability topics to examine from a marketing perspective: external-internal focus, social-environmental emphasis, legal-ethical-discretionary intent, marketing assets and financial performance. There are a small number of textbooks or anthologies that are devoted to CSR communication. Until now the most comprehensive of these contributions to our knowledge is "The Handbook of Communication and Corporate Social Responsibility" (Ihlen et al. 2011) consisting of 28 chapters including two introductory chapters, six chapters presenting field overviews of communication and CSR

\footnotetext{
* Anne Ellerup Nielsen \& Christa Thomsen Department of Business Communication School of Business and Social Sciences Aarhus University Jens Chr. Skous Vej 4 DK-8000 Aarhus C aen@asb.dk-ct@asb.dk
} 
from the perspectives of management communication, organizational communication, marketing communication and public relations, plus chapters focusing on CSR practices, tools and processes. Other contributions worth mentioning in this connection are "Corporate Social Responsibility: Virtue or Vice" (May 2011) and a textbook on CSR communication entitled "Strategic CSR Communication" (Morsing/Bechmann 2006), introducing CSR communication from a strategic stakeholder group perspective (consumers, NGOs, employees, investors etc.). A third anthological contribution is "The Debate over Corporate Social Responsibility" (May et al. 2007), which is anchored in organizational communication and incorporates a conceptual and critical reflection on CSR and CSR communication. However, as pointed out by Ihlen et al. (2011), in most of these textbooks and anthologies, CSR communication has not been subject to research in its own right, which was the primary motivation behind the publication of the first handbook in the field (Ihlen et al. 2011: 5).

This article investigates the streams and themes which dominate in the CSR management and marketing communication research. Reviews of the CSR literature have typically been categorized into groups according to the dominant CSR theme or focus of the articles concerned, for instance social responsibility, environmental responsibility and business ethics (e.g. Egri/Ralston 2008; Lockett et al.,2006; Taneja et al. 2011). This review is categorized into two groups, i.e. CSR management and marketing communication according to the dominant research streams which have influenced the CSR communication research and the dominant CSR communication theme or focus of the articles.

The objective of this article is threefold. First, it examines CSR management and marketing communication research streams and themes. Second, it synthesizes the means by which CSR management and marketing communication activities can add value for stakeholders using the corporate communication framework and the distinction between strategies and operational practices supporting these strategies. Third, it presents a research agenda for future research to allow greater consistency and mutual understanding among CSR communication researchers.

The article is organized as follows: In the next section, the research method is presented, the focus being on the literature collection methodology and the parameters used for reviewing and analyzing the selected literature. After this, the results are presented and discussed with special reference to areas of focus which have been identified in the analysis. The article ends with implications of the study, directions of future research, and contributions.

\section{Research method}

The research method for the study is discussed in the two sub-sections below: a) literature collection methodology, and b) research parameters used for reviewing the selected literature.

\subsection{Literature collection methodology: a two-step keyword search process}

In order to be able to define the streams and themes in the CSR management and marketing communication research, a conventional keyword-based search strategy was adopted. This search strategy is relatively simple and easy to use. However, it may result in a very large number of irrelevant references. In an attempt to avoid this, the following selection criteria were adopted:

- Two-step search process: a) "corporate social responsibility" and "CSR" combined with "management and/or marketing communication"; b) "corporate social responsibility management and/or marketing communication", "CSR management and/or marketing communication".

- International peer-reviewed articles in academic journals (full text, references available).

- Delimitation to the period 2000-2011. 
This was undertaken using the citation search facility of the ABI/INFORM, EBSCO's Business Source Complete and JSTOR, and through reference list searching. The databases selected cover social sciences, the Business Source Complete database being regarded as the dominant database within business and economics.

A total of 314 references were generated in the first broad search for "corporate social responsibility" combined with communication", here called "the large sample" (244 overlapping references for the search for "CSR" combined with "communication"). The search led us to more than 70 international academic journals, the far most dominating journal being Journal of Business Ethics.

From the references generated, articles were selected with the help of thematic content analysis. Articles with a dominant CSR management and marketing communication theme reflected in keywords, titles and abstracts were selected for final review, whereas articles published in sectororiented journals and/or articles focusing on a special product were not included. Moreover, articles written in languages other than English and articles which were either transcribed speeches, comments, book reviews, published in more than one place or insubstantial articles (four pages or less) were automatically excluded.

\subsection{Research parameters for review: corporate communication}

In order to analyze the research streams and themes in the CSR management and marketing communication literature and synthesize the means by which CSR management and marketing communication activities can add value for stakeholders, we have used central concepts and tools from corporate communication (Cornelissen 2011; van Riel 1995).

Corporate communication can be characterized as "a management function that is responsible for overseeing and coordinating the work done by communication practitioners in different specialist disciplines, such as media relations, public affairs and internal communication" (Cornelissen 2011: 5). It has been defined as "an instrument of management by means of which all consciously used forms of internal and external communication are harmonized as effectively and efficiently as possible", with the overall objective of creating "a favourable basis for relationships with groups upon which the company is dependent" (van Riel 1995: 26). Defined in this way, corporate communication constitutes a useful perspective for the analysis of CSR management and marketing communication as a discipline which focuses on "anticipating stakeholders' expectations, articulation of CSR policy and managing of different organization communication tools designed to provide true and transparent information about a company's or a brand's integration of its business operations, social and environmental concerns, and interactions with stakeholders" (Podnar 2008: 75). Corporate communication also offers a useful perspective for evaluating CSR management and marketing communication in a critical integrated perspective. Central concepts and tools from corporate communication used for the analysis are: (i) stakeholder management and communication, corporate identity, corporate branding and corporate reputation; and (ii) communication strategy, strategic planning, measurement, media relations, internal communication, issues management, crisis communication, leadership and change communication etc. The first of these concepts and tools relates to corporate communication in theory, whereas the second relates to corporate communication in practice.

\section{Results: Research streams and themes within CSR communication research}

In this section, the results obtained using the concepts and tools mentioned above are discussed. The focus is on two research fields that are regarded as providing an overview of the themes addressed and the contribution of CSR communication research are identified: the management communication approach to CSR communication and the marketing communication approach to CSR communication. The two fields of CSR management and marketing communication are presented after an introduction to the mere concept of CSR. 
The selected articles within the field of CSR management and marketing communication are divided into two categories: A) strategic use of CSR management and marketing communication; and B) operative use of CSR management and marketing communication. Category A includes studies framing the involvement of strategic management decisions about which policies, processes, CSR goals and corporate communication strategies to follow; while studies of category B have more to do with the media, channels and rhetorical arsenal which are used (or which are appropriate to use) for various contents, situations and purposes.

\subsection{Conceptualizing CSR communication}

Research which explicitly refers to definitions, understandings and interpretations of CSR communication is rare, comprising in fact only a single focused paper (Podnar 2008). The aims of this paper, which is an introduction to a special issue on the communication of CSR in the Journal of Marketing Communications, are "to define the field of Corporate Social Responsibility communication, to emphasize the role of communicating CSR and briefly to describe different perspectives on CSR communication" (Podnar 2008: 75). As mentioned in the introduction, CSR communication is defined as "a process of anticipating stakeholders' expectations, articulation of CSR policy and managing of different organization communication tools designed to provide true and transparent information about a company's or a brand's integration of its business operations, social and environmental concerns, and interactions with stakeholders" (Podnar 2008: 75).

Research which explicitly refers to CSR communication models and/or frameworks is also rare. Morsing et al. (2008) contribute two models that may help to explain how companies can best communicate about their CSR initiatives. Based on a reputation survey and two case studies of Danish corporate CSR frontrunners, the authors develop an inside-out approach to suggest how managers can manage their CSR activities to achieve a favourable CSR reputation. Employees appear as a key component in building trustworthiness as CSR communication evolves when taking an inside-out approach. The authors develop a CSR communication model with two CSR communication processes targeting different stakeholder groups: the expert CSR communication process, and the endorsed CSR communication process. It is argued that integrating these models and processes may help companies to strategically capture reputational advantage from their CSR initiatives. Maon et al. (2010) focus on the impact of IKEA's CSR commitments and communication on different stakeholders. They report that IKEA must be transparent in its commitments and credible in its communication, since different types of stakeholders vary in their perceptions of the organization's CSR. They also suggest the development of more comprehensive CSR models that can be tailored to suit different stakeholders. Highlighting a need for companies to communicate CSR more effectively to stakeholders, Du et al. (2010) present a conceptual framework of CSR communication which takes into consideration message content and communication channels along with company- and stakeholder-specific factors that influence the effectiveness of CSR communication. O'Riordan/Fairbrass (2008) review past attempts to theorize the concept of stakeholder dialogue by identifying gaps and weaknesses in the literature, and by proposing a new analytical model. The central aim of the new model that they propose is to offer a comprehensive approach to CSR decision making while simultaneously providing a practical framework for CSR executives who face the challenge of responding in an effective manner to stakeholders.

The research reviewed above provides insights into the general understanding of CSR communication, an understanding which we would characterize as functionalistic, and into how CSR communication which is tailored to suit different stakeholders may contribute to enhance businesses' image and reputation amongst their customers, employees and other stakeholders. Central concepts are: inside-out communication, endorsement and stakeholder dialogue, and highlighting a need for corporations to pay attention to message content and communication channels. 


\subsection{The management communication approach to CSR communication}

Management communication can be defined as the communication of managers at different levels with internal and external target groups (van Riel 2005: 22). According to van Riel, research has shown how essential the role of managers is in the realization of a positive communication climate and a positive reputation. In line with this, the management communication perspective on CSR communication can be defined as the CSR communication of managers at different levels with internal and external target groups, the purpose being to realize a positive communication climate and a positive reputation. This functionalistic definition has been used for the selection of articles within the management communication perspective on CSR communication. Accordingly, most of the articles with a management communication perspective that we have reviewed

focus on enhancing the corporate image and reputation of the company concerned in the eyes of employees and other stakeholders. Articles with a clear consumer or customer focus are classified as articles within the marketing communication approach to CSR communication, and are reviewed in the corresponding paragraph. Finally, articles with a broader stakeholder focus dealing with issues relevant for the general public are reviewed in the section on the public relations approach to CSR communication.

Contributions within the management communication approach to CSR communication have primarily come from researchers interested in disciplines such as leadership (see conceptual review in Kakabadse et al. 2005), employee relations (Morsing 2006) and stakeholder management (Andriof/Waddock 2003). Researchers generally acknowledge the role of leaders in organizations as very important in ethical issues, especially because of their key influence on the organizational culture (Kakabadse et al. 2005). According to Kakabadse et al., leadership shapes and orients the organizational climate so that the expectations of organizational constituents match more socially accepted norms of behaviour. For instance, leaders must embody CSR values, promoting and supporting them through their own behaviour and attitude. Consequently, leadership is required at more than one level in an organization, which suggests that not only top executives but also middle managers and others must fully endorse the values of the organization. Researchers also acknowledge the role of managers as important in the relationships that companies have with stakeholders (Andriof/Waddock 2003: 19). Perspectives on stakeholder theory have moved away from an entirely corporate-centric focus in which stakeholders are viewed as subjects to be managed, towards more of a network-based, relational and process-oriented view of company-stakeholder engagement, where at least there is some consideration of mutuality, interdependence and power. Within the above framework, researchers have focused on topics such as CSR communication strategies and stakeholder engagement or involvement (e.g. Morsing/Schultz 2006), stakeholder dialogue (e.g. Kaptein/van Tulder 2003; Rahbek Pedersen 2006), new social partnerships (Zadek 2001; Googins/Rochlin 2000) and corporate social reporting (see a review of the literature in Gray et al. 1995; Nielsen/Thomsen 2007). Below, we review selected articles within the management communication approach to CSR communication.

\subsubsection{Strategic use of CSR management communication}

Research within this category focuses on CSR communication as a means to avoid negative impacts or counter negative publicity efforts, and to develop legitimacy, a positive reputation, lasting stakeholder relationships, credibility and the identification or engagement of employees. Other topics are the role of the media, stakeholder dialogue, and how to frame responsibility strategies.

In a study of the views of management teams in large companies, Arvidsson (2010) finds that companies engage in CSR activities to avoid negative impacts instead of being driven by a will to achieve social improvements or act in a manner that is fundamentally believed to be right. Morsing and Schultz (2006) develop three CSR communication strategies. Based on empirical illustrations and prior research, the authors argue that managers need to move from informing and responding to involving stakeholders in CSR communication itself. They conclude that managers need to expand the role of stakeholders in corporate CSR communication processes if they 
want to improve their efforts to build legitimacy, a positive reputation and lasting stakeholder relationships. Mamantov (2009) discusses ways to achieve the engagement of employees. The author mentions the utilization of emotional relationships and the encouragement of collaboration through community and demonstration of underlying value as factors in CSR communication strategy that will help companies to attain their employees' objectives. The article also notes that the connection between the employers and employees is important in the process. Morsing (2006) suggests that communicating corporate CSR efforts via external stakeholders is one of the most powerful communication strategies currently available to improve member identification, or to cause disidentification. While CSR messages indeed communicate to external stakeholders, they also serve internal purposes such as reinforcing corporate identity and building identification among organizational members. Through a review of CSR, corporate identity, corporate communication and stakeholder literature, Johansen/Nielsen (2011) develop a framework which takes into account the different stakes held by key stakeholder groups, i.e. consumers, investors, employees, non-governmental organizations and suppliers. Based on the discursive terms of form and script, the authors argue that different stakes condition different dialogical types. The authors argue furthermore that the stakeholder orientations of the CSR, corporate identity and corporate communication disciplines can help to strengthen dialogue. It is suggested that dialogue may be strengthened by constructing a framework which links the stakes held by key stakeholder groups to specific dialogue forms and scripts. Fieseler (2011) looks at how equity analysts at the German stock exchange in Frankfurt perceive economic, legal, ethical and philanthropic responsibility strategies. The evidence obtained suggests that responsibility issues are increasingly becoming part of mainstream investment analysis. However, for them to play a larger part in the future, investor relations personnel must frame responsibility strategies in a way that is more consistent with the financial community's perspective. In particular, the impact of CSR measures on strategic development, competitive anticipation and creating trust with stakeholders are key in leveraging CSR in financial communications. In a study of CSR and green management, Cruz/Pedrozo (2009) propose five challenges that must be faced by multinational companies (MNCs) when managing CSR communication strategies. The challenges are related to the link between literature and three dimensions and five sub-dimensions that emerged from the two cases studied: the governance structure (the structure of the CSR department and dialogue with stakeholders); corporate ethics (the definition of objectives and corporate posture); and organizational learning (awareness and information exchanged about CSR). Finally, Fassin/Buelens (2011) address the frequently perceived discrepancy between the CSR walk and talk of companies, resulting in a hypocrisy-sincerity gap in their corporate communication and decision-making. According to the authors, there is a need for improved CSR evaluation systems taking into account the hypocrisy content of company communication. An analysis of why the discrepancy occurs sheds light on the role of communication and the perception of hypocrisy. A model of a sincerity-hypocrisy index is suggested in order to position the company on a continuum from idealism to hypocrisy, which could help practitioners generate better CSR communication strategies.

The research reviewed above generally provides insights into important communicative aspects of strategic CSR management communication, aspects such as: the importance of a "CSR history", the need to involve stakeholders, the importance of championship by senior management, and the importance of having a credible CSR programme. The media's role (newspapers, business magazines etc.) and concepts such as emotional relationship, member identification and message framing are highlighted.

\subsubsection{Operative use of CSR management communication}

Research within this category focuses on issues such as communicative behaviour, corporate websites, corporate blogs, corporate reporting and stakeholder dialogue.

According to Ziek (2009), the literature on CSR and CSR communication is diverse and encompasses a plethora of theories and approaches. It is still unclear how organizations explicitly 
communicate the behaviour that constitutes CSR. The author provides an illustration of the accounts that constitute CSR communication. It is demonstrated that communicating CSR is limited to large organizations, and that primarily they communicate CSR by conveying information about classically accepted responsible and virtuous behaviour. The author concludes that this patterned communicative behaviour is a process that organizations engage in to make sense of CSR. Wanderley et al. (2008) argue that corporations are increasingly concerned with communicating ethically and responsibly to their diverse stakeholders through the web. They address the question of whether CSR information disclosure on corporate websites is influenced by country of origin and/ or industry sector, and find that both country of origin and industry sector have a significant influence on CSR information disclosure on the web. Fieseler et al. (2010) use social network analysis to examine the interaction between corporate blogs devoted to sustainability issues and the blogosphere, a clustered online network of collaborative actors. By analyzing the structural embeddedness of a prototypical blog in a virtual community, they demonstrate the potential of online platforms to document CSR activities and to engage with an increasingly socially and ecologically aware stakeholder base. Pedersen (2006) examines how corporations translate CSR into actual practice. It is shown how a company's consciousness, ability, willingness and interests may affect the success of stakeholder dialogue initiatives. In their article from 2006, Burchell/Cook discuss company and NGO attitudes towards stakeholder engagement processes, and the impact that this has had in changing organizational practices. The authors look at the types of dialogue being undertaken, the links between dialogue and trust, and the role of dialogue in shaping organizational learning. In general, the findings present an overview of the current perception of dialogue within the field of CSR. O'Connor/Spangenberg (2008) present a framework called the CSR Deliberation Matrix for the structuring of CSR issue identification, stakeholder dialogues, indicator selection and reporting, with an overarching goal to achieve an appropriate balance between sensitivity to individual situations and the benefits of "generic" indicators applicable to a large spectrum of reporting contexts. Hughes/Demetrious (2006) examine two stakeholder software packages, showing how each one's rhetoric of inclusion accompanies discourses that recreate adversarial relationships between organizations and stakeholders. The article sets such developments against the broad backdrop of developing notions of CSR, arguing that the uncritical use of stakeholder communication packages can reduce CSR to mere PR spin.

The research within this category highlights the following aspects: the importance of CSR communication behaviour; the fact that country of origin and industry sector have a significant influence on CSR information disclosure on the web; the potential of online platforms to document CSR activities and to engage with stakeholders; the fact that a company's consciousness, ability, willingness and interests may affect the success of stakeholder dialogue initiatives; and finally the role of dialogue and discourse. The research also highlights a distinction between country-specific and sector-, firm- and industry-specific approaches. A study of CSR communication intensity in Chinese and Indian multinational companies (Lattemann et al. 2009) demonstrates that the macro institutional environment in a country strongly affects CSR behaviour. The study suggests that in order to improve the CSR of firms, policy makers in India and China must first try to improve public governance at the national level. Executives doing business with Chinese and Indian companies need greater understanding of contrasting governance and their effects on the CSR practices in each country. For the international community and those concerned about product safety and other social issues related to China and India, the findings suggest that improvement will not be immediate since the governance environment in these countries changes relatively slowly. A study of the CSR communication of corporate enterprises in Hungary (Ligeti/Oravecz, 2009) concludes that the reason for difficulties in finding the best CSR solutions for enterprises and creating the commitment of their employees for the cause undertaken is that they do not think of CSR as a consequence of ethical core business process, but rather as a separate task they try to complete aiming at short-term results and maximum benefits. A comparative study of Indian companies' and multi-national corporations' communication in annual reports (Tewari 2011) finds that 
both Indian companies and MNCs target and attach importance to a similar group of stakeholders for their CSR communication, but that the area of focus for specific stakeholders varies. With regard to human resources, MNCs tend to address the quality of working life, while Indian companies focus upon the monetary benefits provided. With regard to customers, the focus of MNCs is placed on product quality, while Indian companies focus upon price as a parameter. Birth et al. (2008) provide a picture of the practice of CSR communication among the top 300 companies in Switzerland, and investigate how favourable the cultural context is for this kind of communication. The authors find that CSR communication in Switzerland appears to be well developed, but still has broad margins for development. It is argued that the elements that should be considered in order to develop effective CSR communication are: synergies between issues, objectives, and channels; criteria for a credible social report; the exploitation of the potentialities of CSR advertising and the web; and the understanding of the national context where the organization is operating. Shaomin et al. (2010) examine the way in which country-level, industry-level and firmlevel factors affect the extent of corporate communications about CSR in Brazil, Russia, India and China (known as the "BRIC" countries). The study reveals that a country's governance environment is the most important driving force behind CSR communications intensity. The authors conclude that firms communicating CSR tend to be major firms in the manufacturing industry in more rule-based societies. These firms also tend to have stronger corporate governance as measured by a high proportion of outside board directors and a separation of the roles of the chairman and the CEO.

The above country-specific approaches generally outline different practices in different countries, thus highlighting the role of the national context. Aspects such as the macro institutional environment and the governance structure affect companies' approach to CSR communication, which is also argued by Matten and Moon in their article from 2008 on implicit and explicit CSR (Matten/Moon 2008).

In line with this, sector-, firm- and industry-specific approaches generally outline different practices in different sectors, firms and industries. The article by Nielsen/Thomsen (2009) analyses small- and medium-sized enterprise (SME) managers' representations of CSR and CSR communication in a corporate communication perspective. The analysis shows that SME managers clearly have an inside-out approach to CSR, with a strong emphasis on the internal (corporate culture) dimension. However, SMEs and/or SME managers tend not to communicate externally about their CSR activities. Based on these findings, the paper argues that CSR communication in SMEs is challenged by the global economy and is under revision. Da Silva et al. (2007) investigate CSR communication through an analysis of websites in Brazil and the UK, exploring three multinational companies in the oil industry operating in both countries. The authors analyse these firms' CSR communications via websites in order to examine not only the consistency of content and design, but also specific resources of the Internet media. While the analysis, interpretation and discussion of the research questions demonstrate that a number of features converge in both countries, the authors also find that in the oil industry CSR communication is more highly developed in the UK than in Brazil. In a case study of the top 100 information technology companies in India, Chaudhri/Wang (2007) find that the number of companies with CSR information on their websites is strikingly low, and that these leading companies do not leverage their websites to their advantage in terms of the quantity and style of CSR communication. Although the findings do not necessarily imply the absence of CSR action on the part of IT companies in India, they attest to a general lack of proactive CSR communication. The article concludes with managerial implications for CSR communication on corporate websites. Focusing on CSR in SMEs, Fassin (2008) suggests on the basis of an ethnographic field analysis that the argument for expanding the formalisation of CSR to SMEs rests upon several fallacies. It implicitly assumes that an apparent solution for large multinationals can be transposed to SMEs, and it underestimates the drawbacks of bureaucracy. Moreover, many SMEs experience inconsistency between the idealistic CSR communication of some large companies and their actions, especially in the supply chain. The author 
concludes that reports do not constitute any validation for real CSR, or any proof of superior ethical behaviour. Formalisation can even be counterproductive. Conversely, the absence of social reporting does not imply that SMEs do not behave responsibly. CSR in SMEs needs a specific approach, adapted to the informal nature and entrepreneurial character of the small business. The essence of CSR lies in the implementation of responsible business practices. It lies in the right attitudes, in the corporate culture, not in formalisation. Abu Bakar/Ameer (2011) examine the readability of CSR communication (disclosure) for a sample of listed companies in Malaysia, and find that the management of poorly performing companies deliberately choose difficult language in their CSR communication. The study contributes to research in CSR literature by enumerating the syntactical difficulties in corporate annual CSR communications. The study by Sweeney/ Coughlan (2008) considers the content of the annual report and looks at how organizations take a focused stakeholder view of CSR rather than a wider view as would be expected from the ambiguity of definitions of the concept. Findings show that there is a significant difference between the way in which different organizations in different industries report on CSR, and that this reporting follows for the most part the expectations of the CSR communications literature. It is suggested that firms report on CSR in line with what their key stakeholders expect, thus lending weight to the idea that CSR reporting is another tool in the marketing communicator's toolbox. O'Connor/ Shumate (2010) identify the similarities and differences in CSR communication at the institutional and economic industry level of analysis. Their findings suggest that at the institutional level of analysis, a corporate consensus exists about the scope of CSR, which is largely understood as welfare capitalism. However, at the economic level of analysis, differences across industries exist based on their position in the value chain. Specifically, industries further up the value chain focus on the safety of their employees, ethical business practices and environmental stewardship as essential elements of CSR; whereas industries closer to customers in the value chain are more likely to focus on philanthropy and education as CSR. Another study explores how organizations explain the motives behind their CSR activities in order to gain legitimacy in society (Ingenhoff/ Sommer 2011). A content analysis of companies' annual and CSR reports is undertaken in order to examine reported social activities in the financial and pharmaceutical industries. A quantitative survey analysis allows the authors to examine what potential stakeholders expect with regard to social engagements in these two industries. The result of the study is that societal and environmental issues are the most reported engagements in the two industries, and that this largely responds to the expectations of stakeholders.

The major insight gained from the research within the field of CSR management communication is that modern companies do not seem to have moved from the reactive, compliance-oriented management of CSR communication towards proactive, stakeholder-oriented CSR communication (e.g. Andriof/Waddock 2003: 42). CSR management communication is primarily viewed as a process for managing a company's social risk (for instance), and only to a minor extent as a process for connecting with stakeholders.

\subsection{The marketing communication approach to CSR communication}

Marketing communication can be identified as direct sales-supporting communication aimed at influencing customers and increasing sales (van Riel op. cit.). A significant stream of the research within the marketing approach to CSR communication is grounded within consumer behaviour studies, with the "green" segment research stream from the early 1980s introducing studies of the green movement (green products, energy conservation, waste handling, knowledge measurements, motivation, peer influence, cost-benefit etc.) (Bechmann 2006: 168). Following this, marketing is often met with suspicion and cynicism when attempting to convey messages with CSR content as a means of creating a more socially responsible image (e.g. Jahdi \& Ackikdili, 2009). Consequently, many of the marketing communication studies in this paper make suggestions about how companies can strengthen and improve their CSR communication while overcoming subsequent consumer scepticism. 
Consumer reactions to CSR initiatives in terms of awareness, attitude, purchase etc. have thus been subject to several studies (e.g. Bhattacharya/Sen 2004a/2004 b; Yoon/Gürhan-Canli 2004; Davar/Klein 2004; Creyer/Ross 1997). As demonstrated in the present study, this tendency also seems to continue in more recent studies within the field. The characteristic of this stream of research is its focus on the development and use of methods which can explain and measure the effect of corporations' CSR initiatives and communication on consumers.

Articles that are categorized within the marketing approach to CSR communication have in common the premise of conceptualizing CSR communication as a framework or tool that can be used in order to improve consumers' assessment of companies' products and/or corporate brands. Accordingly, the primary purpose of articles within this category is to register, measure and/or discuss consumers' attitudes, beliefs and/or assessments of CSR communication. In general, their primary purpose is to demonstrate how the use of specific CSR communication and communication-related strategies by companies is likely to affect consumers' knowledge or assessment of companies and/or their practices of CSR communication. For this reason we have considered most of the contributions to be non-strategic and operational, as they address the mutual influence of CSR communication and other stand-alone factors on consumers. In other words, they do not help to conceptualize CSR communication from a corporate branding perspective, including coordination of identity, value and reputation-based management processes.

Eight of the articles in this small sample specifically address marketing issues, and will be introduced and commented on below.

\subsubsection{Strategic use of CSR marketing communication}

Only one of the articles that we have selected from our sample addresses CSR marketing communication as a strategic issue. This is an article written by Maignan and Ferrell (2004). It sets out to establish a conceptual framework for how CSR can be integrated more strategically into the marketing discipline. The authors discuss how management processes can help to adjust CSR initiatives to suit the needs and expectations of both stakeholders and the organization concerned with the aim of creating increased stakeholder support. They recommend that future research in marketing and CSR should include more in-depth studies of stakeholders in the broad sense: stakeholder community, stakeholder norms, or stakeholder power. Their contribution is thus to approach CSR marketing research and practice from a more stakeholder-oriented perspective.

\subsubsection{Operational use of CSR marketing communication}

All the articles listed in this stream address CSR marketing communication in terms of the effects produced on consumers' perception of CSR communication and/or the CSR communicating company. Marketing communication studies of CSR communication are thus largely characterized by effect and behavioural studies measuring the effects of CSR and CSR communication on different sales parameters. Their scope is on strategically determining the factors and combination of factors that influence how consumers perceive and respond to companies that practice CSR. Other studies focus on introducing the forces and drivers behind the development of CSR communication as a potential of image and reputation enhancement amongst consumers, which constitutes a more analytical and descriptive approach to examining CSR communication in a marketing context The argument here is that image and reputation enhancement may lead to increased sales and thus increased profits (Kramer/Porter 2006).

Parquel et al.'s article (2011) investigates the effects of sustainability ratings on consumers' response to companies' CSR communication. Experimental results indicate that companies with poor sustainability ratings get negative corporate brand evaluations in terms of CSR communication by consumers who attribute less intrinsic motives to these brands. Consequently, the authors argue that companies could pay more attention to sustainability ratings in order to determine what has been perceived as "greenwashing" and encourage them to continue to practise CSR. 
Two studies examine the effect of company-consumer identity and values on consumers' behaviour and attitudes towards companies that practise CSR communication. The first study, by Golob et al. (2008), sets out to examine the effect of values and issue involvement on consumers' expectations concerning economic, legal, ethical and philanthropic CSR activities. They find that expectations are particularly high in the legal and ethical-philanthropic domains, and that the latter of these expectations are proportional to the self-transcendent values and involvement of the consumer. The importance of recognizing the values and expectations of consumers and other stakeholders regarding CSR communication is therefore pointed out by the authors. The second study is by Currás-Térez et al. (2009). It analyses the influence of consumers' perception of CSR on their identification with the corporate brand and purchase intention in question. It is found that CSR is likely to create company-consumer identification because it improves brand prestige and distinctiveness, and finally that company-consumer identification may generate a more positive attitude towards a brand and thus increase the level of purchase intention.

The last publication in this group is Smith et al.'s study (2010). Contrary to the articles above, their article adopts a critical analytical approach to examining and discussing the effect of marketing on consumers and vice versa. A backlash against brands seems to be provoked by consumer criticism of CSR marketing and unsolved problems in the supply chains of large corporations (working conditions in sweatshops and downstream marketing). The authors suggest a range of recommendations in order to respond to these problems. They are both caused by and call for solutions within marketing and for further research to fill the gap between CSR-oriented corporations and their supply chains.

One common contribution of the articles above is their disclosure of elements and features that have been found to have an influence on consumers' perception of CSR and companies practising CSR and communication, Accordingly they recommend marketing methods that may be particularly successful for how to measure and unfold this perception. This group also includes studies that are country-, culture- or sector-specific. Becker-Olsen et al. (2011) examine the effects of marketing-oriented CSR communication on consumers' brand perception in two different cultures: the US and Mexico. Based on global brand positioning theory, the authors conclude that multinational companies that focus on global CSR efforts engender a more positive perception, but that a certain degree of local adaptation of CSR is necessary. Nonetheless, the authors point out that the differences observed for consumers in the two cultures are relatively small, and that future studies should consider using additional qualitative data to gain insights into potential values and meanings underlying the result of their study. The study thus contributes to methodologically fine-tune the criteria adopted for the research and practice of cross-cultural consumer studies. A sector-specific study undertaken by Wang (2009) in the mobile phone sector investigates the effects on consumers' perception of three CSR practices (ethical, discretionary and relational) on their attitude towards mobile phone companies. The study concludes that ethical and relational practices are considered to have a more positive effect than discretionary practices on consumers' attitudes towards these companies, and that companies should consequently integrate ethical and relational elements into their CSR communication practices. Another study is a channel-specific study of CSR advertisements over time (Mogele/Tropp 2010), which is not conceptualized within the effect perspective. Its scope is operational CSR marketing communication. It explores the development of CSR advertisements in three selected German magazines in the period 2002-2007. This study is based on content analysis, and its findings show that the share of CSR print advertisements has increased by no less than $390 \%$. In the light of this massive increase, the study concludes that companies do manifest a will to engage in CSR and that this development bears witness to the emergence of an ethical economy. The value of this kind of temporal study cannot be overestimated in new fields, whose future existence or disappearance may be determined by signs of stabilization or change. A significant increase over time may indicate that CSR communication may emerge as a consisting field of research and interest amongst practitioners. 
As shown in the list above, the studies reviewed within a marketing communication approach are primarily based on classical and functionalistic perspectives in which instrumental measures such as "more information about CSR" and/or "alternative message contents" are expected to result in changed consumer perception of the corporate image and/or CSR stance of a company.

\section{Discussion and Conclusion}

Our review of the CSR communication literature has outlined management and marketing approaches to CSR communication, focusing on topics that have been included in the research. In particular, the review has synthesized the means by which CSR communication activities can add value for stakeholders, the focus being on employees, consumers and stakeholders in general.

Although the review is restricted to a small sample of articles, its strict focus on CSR communication provides insights into CSR communication as an emerging field. It demonstrates that the number of publications on the subject has significantly increased, especially during the last three to four years. 44 out of the small sample of 54 articles on CSR communication were published in 2008 (12), 2009 (9), 2010 (12) and 2011 (11).

Research on CSR communication focuses on the concept of CSR communication and on how to use CSR communication, the purpose being to enhance businesses' image and reputation among their customers, employees and other stakeholders - a purpose which CSR communication shares with that of corporate communication. Central concepts are: inside-out communication, endorsement and stakeholder dialogue, highlighting a need for corporations to pay attention to communication channels. Important communicative aspects of strategic CSR management communication are highlighted, e.g. CSR history, the need to involve stakeholders, the importance of championship by senior management, and the importance of having a credible CSR programme. The media's role and concepts such as emotional relationship, member identification and message framing are also central in the CSR communication research.

The review demonstrates that research on the importance of country of origin and industry sector is increasing, the focus being on topics such as: CSR information disclosure on the web; the potential of online platforms; the fact that the company's consciousness, ability, willingness, and interests may affect the success of stakeholder dialogue initiatives; and the role of dialogue and discourse. Different practices in different countries and sectors, firms or industries are outlined, highlighting the role of the national and institutional context. Research clearly demonstrates that aspects such as the macro institutional environment and the governance structure seem to affect companies' approach to CSR communication.

One insight gained from the review of the research within the field of CSR communication is that modern companies still do not seem to have moved from the reactive, compliance-oriented management of CSR communication towards proactive, stakeholder-oriented CSR communication (e.g. Andriof/Waddock 2003: 42). CSR communication is primarily viewed as a process for managing a company's social risk, for instance, and only to a minor extent as a process for connecting with stakeholders. The review shows, for example, that studies within the marketing and public relations communication approach are primarily based on a classical and functionalistic perspective in which instrumental measures such as "more information about CSR" and/or "alternative message contents" are expected to result in changed consumer perception of the corporate image and/or CSR stance of a company. None of the studies seem to challenge the functionalistic behavioural pattern by turning towards more interpretative and co-creational marketing approaches, or towards considering CSR as a social function integrating equally corporations' and society's objectives (Gond/Matten 2007). CSR marketing communication is regarded as an add-on tool rather than a product of co-creation. In order to bring CSR marketing communication into more postmodern approaches, CSR marketing communication research might benefit from consumer culture studies, which take the consumer into account as a co-producer of meaning and interpretation (e.g. Caruana/Crane 2008; Moisander/Pesonen 2002). Rather than investigating the impact 
and perception of CSR communication, postmodern marketing and consumer culture are less concerned with the effects of using specific tools and strategies and more focused on how consumers make sense of CSR (Caruna/Crane 2008).

Another important insight from the study is that an overwhelming number of the reviewed articles address CSR communication processes as a strategic or operational management issue rather than as a marketing or public relations issue. It thus seems that managing and planning CSR communication to and with different stakeholders through different channels and media represent a significant challenge for businesses, which obviously call for models and tools that are appropriate for different types, targets and contexts of CSR communication. From a corporate communication perspective, our review also demonstrates that CSR communication is by no means addressed as a strategic integrated field of the organization's communication activities. It clearly appears that the majority of reviewed articles are operational and context specific, and consequently that the role attributed to communication is tool oriented rather than being strategy oriented. Furthermore, although the stakeholder perspective is embedded in several of the reviewed articles, stakeholders are approached in segments and not from a coordinated and integrated perspective. This leads us to the conclusion that CSR communication at its present stage is hardly ever investigated or practised as corporate communication as defined above.

Finally, insights about what causes the delicacy of communicating CSR are highlighted in the study: CSR marketing communication is a delicate issue that may have a negative impact on consumers' perception of companies and the focus on factors that contribute to make consumers swallow CSR claims more easily. The focus on this issue is also seen in the light of the challenges embedded in CSR communication as public relations. Perceived by many stakeholders as spin or a "PR stunt" (Frankental 2001), CSR communication is subject to hypocrisy (Fassin/Buelens 2011). In trying to comply with increasing demands for CSR information by stakeholders, companies which convey extensive CSR messages about their social activities risk creating a backlash when stakeholders consider them to be excessively self-promotional - something which has been referred to as "the CSR promotional communication dilemma" (Coombs/Holladay 2011: 110). However, the absence of more distinct understandings of how CSR communication contributes to marketing communication and public relations in relation to traditional instruments and discussions about the interrelationships between the co-existence of these fields is significant. Further insights into this issue might help to sharpen the objective and form of CSR communication.

On the basis of this, we believe that studies within the following areas or topics could take CSR communication research a step forward:

- Studies that link CSR communication to a broader and more holistic concept of corporate communication and related fields (i.e. stakeholder interaction, corporate branding, public relations etc.)

- Studies that provide more in-depth insights into the stakeholder benefits and values of CSR

- Studies of CSR communication as a social practice

- Studies of message and media factors, e.g. the characteristics and appropriateness of channels and media for CSR messages/interaction and the appropriateness of rhetorical elements

- Company fit studies: studies of company fit (business line and cause), identity fit (corporateconsumer identity), cultural fit (national differences and pressures), sector fit (industrial differences and pressures) and company size

- Until more substantial studies like those listed above have been undertaken, it is not an easy task for researchers and practitioners to conceptualize, plan, design and practise CSR communication activities as a field that can add value for stakeholders within a corporate communication framework. 


\section{References}

Abu Bakar, A.S./Ameer, R. 2011: Readability of Corporate Social Responsibility Communication in Malaysia. In Corporate Social Responsibility \& Environmental Management 18(1), 50-60.

Andriof, J./Waddock, S. 2003: Unfolding Stakeholder Engagement. In Andriof, J./Waddock, S./Husted, B.,/Rahman , S.R. (eds.), Unfolding Stakeholder Thinking. Sheffield: Greenleaf Publishing, 19-42.

Arvidsson, S. 2010: Communication of Corporate Social Responsibility: A Study of the Views of Management Teams in Large Companies. In Journal of Business Ethics 96 (3), 339-354.

Balmer, J.M.T./Greyser, S.A. 2006: Corporate marketing: Integrating corporate identity, corporate branding, corporate communications, corporate image and corporate reputation. In European Journal of Marketing 40 (7/8), 730-741.

Beadle, R./Ridderbeekz, R. 2001: CSR communication in a controversial sector. In Strategic Communication Management 5 (5), 20-24.

Becker-Olsen, K.L./Taylor, C.R./Hill, R.P. /Yalcinkaya. G. 2011: A Cross-Cultural Examination of Corporate Social Responsibility Marketing Communications in Mexico and the United States: Strategies for Global Brands. In Journal of International Marketing 2, 30-44

Bendell, J. 2010: World Review. The use of CSR communication. In Journal of Corporate Citizenship 40, 6-25.

Bhattacharya, C.B./Sen, S. 2004: Doing better at doing good: when, why, and how consumers respond to corporate social initiatives. In California Management Review 47(1).

Bhattacharya, C.B./Sen, S. 2004: Measuring the effectiveness of corporate social initiatives: a consumer-centric perspective. In Advances in Consumer Research 31.

Bhattacharya, C.B./Korschun, D./Sen, S. 2009: Strengthening Stakeholder-Company Relationships Through Mutually Beneficial Corporate Social Responsibility Initiatives. In Journal of Business Ethics 85, 257-272.

Birth, G./Illia, L./Lurati, F./Zamparini, A. 2008: Communicating CSR: practices among Switzerland's top 300 companies. In Corporate Communications: An International Journal 13 (2), 182-196.

Burchell, J./Cook, J. 2006: Assessing the impact of stakeholder dialogue: changing relationships between NGOs and companies. In Journal of Public Affairs 6 (3/4), 210-227.

Caruana, R./Crane, A. 2008: Constructing Consumer Responsibility: Exploring the Role of Corporate Communications, Organization Studies 29, 1495-1519.

Chabowski, B.R./Mena, J.A./Gonzales-Padron, J.A. 2011: The structure of sustainability research in marketing, 19582008: a basis for future research opportunities. In Journal of the Academy of Marketing Science 39 (1), 55-70.

Chaudhri, V. /Wang, J. 2007: Communicating Corporate Social Responsibility on the Internet: A Case Study of the Top 100 Information Technology Companies in India. In Management Communication Quarterly 21(2), 232-247.

Cheney, G./Christensen, L.T. 2000: Public Relations as Contested Terrain. In Heath, Robert (ed.), Handbook of Public Relations. London: Sage Publications.

Christensen, L.T./Morsing, M./Thyssen, O. 2011: The polyphony of corporate social responsibility. Deconstructing accountability and transparency in the context of identity and hypocrisy. In Cheney, G./May, S./Munshi, D. (eds.), Handbook of Communication Ethics. New York: Lawrence Erlbaum Publishers, 457-474.

Clark, C.E. 2000: Differences Between Public Relations and Corporate Social Responsibility: An Analysis. In Public Relations Review 26 (3).

Cornelissen, J. 2011: Corporate communications. Theory and Practice. London: Sage Publications.

Crane, A. 2011: Researching CSR and Communication: Challenges and Opportunities. Keynote. CSR Communication Conference. Amsterdam, 26-28 October 2011.

Creyer, E.H./Ross, W.T. 1997: The influence of form behaviour on purchase intention: do consumers really care about business ethics? In Journal of Consumer Marketing 14/16, 421-32.

Cruz, L.B./Pedrozo, E.A. 2009: Corporate social responsibility and green management. In Management Decision 47 (7), 1174-1199.

Currás-Pérez, R./Bigné-Alcañiz, E./Alvarado-Herrera, A. 2009: The Role of Self-Definitional Principles in Consumer Identification with a Socially Responsible Company. In Journal of Business Ethics 89 (4), 547-564.

Dawar, N./Klein, J.G. 2004: The role of corporate social responsibility in consumers', attribution and brand evaluation after a product-harm crisis. In Advances in Consumer Research 31.

Da Silva, F.F.A./Perks, K./Berry, A. 2007: Corporate social responsibility communication: How corporations in the oil industry publicise their actions in the UK and Brazil. In International Journal of Business Research 7(2), 25-34.

Du, S./Bhattacharya, C.B./Sen, S. 2010: Maximizing Business Returns to Corporate Social Responsibility (CSR): The Role of CSR Communication. In International Journal of Management Reviews 12(1), 8-19. 
Egri, C.P./Ralston, D.A. 2008: Corporate responsibility: A review of international management research from 1998 to 2007. In Journal of International Management 14(4), 319-339.

Fassin, Y. 2008: SMEs and the fallacy of formalizing CSR. In Business Ethics: A European Review 17(3), 364-378.

Fassin, Y./Buelens, M. 2011: The hypocrisy-sincerity continuum in corporate communication and decision-making - A model of corporate social responsibility and business ethics. In Management Decision 49(4), 586-600.

Fieseler, C./Fleck, M./Meckel, M. 2010: Corporate Social Responsibility in the Blogosphere. In Journal of Business Ethics 91(4), 599-614.

Fieseler, C. 2011: On the corporate social responsibility perceptions of equity analysts. The strategic use of CSR communication. In Business Ethics: A European Review 20(2), 131-147.

Frankental, P. 2001: Corporate Social Responsibility - a PR invention? In Corporate Communications: An International Journal 6 (1), 18-23.

Global Leaders 2010 2010: Business \& the Environment with ISO 14000 Updates 21(11), 5-6.

Golob, U./Lah, M./Jančič, Z. 2008):Value orientations and consumer expectations of Corporate Social Responsibility. In Journal of Marketing Communications 14(2), 83-96.

Gond, J-P./Matten, D. 2007: Rethinking the business-society interface: beyond the functionalist trap. Research Paper Series: International Centre for Corporate Social Responsibility 47, (Nottingham University Business School, Nottingham).

Googins, B.K./Rochlin, S.A. 2000: Creating the Partnership Society: Understanding the Rhetoric and Reality of CrossSectoral Partnerships. In Business and Society Review 105(1), 127-144.

Gray, R./Kouhy, R./Lavers, S. 1995: Corporate social and environmental reporting. A review of the literature and a longitudinal study of UK disclosure. In Accounting, Auditing \& Accountability Journal 8(2), 47-77.

Grunig, J.E./Hunt, T. 1984: Managing public relations. Belmont: Wadsworth/Thomson Learning.

Heath, R. 2000): Shifting Foundations: Public Relations as Relationship Building. In Heath, Robert (ed.), Handbook of Public Relations. London: Sage Publications.

Hughes, P./Demetrious, K. 2006: Engaging with Stakeholders or Constructing Them? In Journal of Corporate Citizenship 23, 93-101.

Ingenhoff, D./Sommer, K. 2011: Corporate Social Responsibility Communication. In Journal of Corporate Citizenship, 42, 73-91.

Jahdi, K.S./Acikdilli, G. 2009: Marketing Communications and Corporate Social Responsibility (CSR: Marriage of Convenience or Shotgun Wedding? In Journal of Business Ethics 88, 103-113.

Johansen, T.S./Nielsen, A.E. 2011: Strategic stakeholder dialogues: a discursive perspective on relationship building. In Corporate Communications: An International Journal 16(3), 204-217.

Kakabadse, N.K./Rozuel, C./Lee-Davies, L. 2005: Corporate social responsibility and stakeholder approach: a conceptual review. In International Journal of Business Governance and Ethics 1(4).

Kaptein, M./Tulder, R.V. 2003: Toward Effective Stakeholder Dialogue. In Business and Society Review 108(2), 203224.

Lattemann, C./Fetscherin, M./Alon, I./Shaomin, L./Schneider, A-M. 2009: CSR Communication Intensity in Chinese and Indian Multinational Companies. In Corporate Governance: An International Review 17(4), 426-442.

Ligeti, G./Oravecz, A. 2009: CSR Communication of Corporate Enterprises in Hungary. In Journal of Business Ethics 84(2), 137-149.

Lockett, A./Moon, J./Visser, W. 2006: Corporate social responsibility in management research: focus, nature, salience and sources of influence. In Journal of Management Studies 43, 115-136.

Maignan, I./Ralston, D.A. 2002: Corporate Social Responsibility in Europe and the U.S.: Insights from Businesses' Self-presentations. In Journal of International Business Studies 33(3), 497-514.

Maignan, I./Ferrell, O.C. 2004: Corporate social responsibility and marketing: an integrative framework. In Journal of the Academy of Marketing Science 32(1), 19-23.

Mamantov, C. 2009: The engine behind employee communication SUCCESS. In Communication World 26(5), 33-35.

Maon, F. Lindgreen, A./Swaen, V. 2010: IKEA's Road to Corporate Social Responsibility (CSR): The Role of CSR Communication. In Retail Digest 76-83.

Matten, D./Moon, J. 2008: "Implicit" and "explicit" CSR: a conceptual framework for a comparative understanding of corporate social responsibility. In Academy of Management Review 33 (2), 404-424.

May, S.K. 2011: Corporate Social Responsibility: Vice or virtue? Cambridge, UK: Polity Press. 
May, S.K./Cheney, G./Roper, J. 2007 (eds.): The debate over corporate social responsibility. New York. NY: Oxford University Press.

Middlemiss, N. 2003: Authentic not cosmetic: CSR as brand enhancement. In Brand Management. 10(4-5), 353-361.

Mogele, B./Tropp, J. 2010: The emergence of CSR as an advertising topic: A longitudinal study of German CSR advertisements. In Journal of Marketing Communications 16(3), pp. 163-181.

Moisander, J./Pesonen, S. 2002: Narratives of sustainable ways of living: constructing the self and the other as a green consumer. In Management Decision 40(4), 329-342.

Moreno, A./Capriotti, P. 2009: Communicating CSR, citizenship and sustainability on the web. In Journal of Communication Management 13(2), 157-175.

Morsing, M. 2003: Conspicuous Responsibility: Communicating Responsibility - To Whom? In Morsing, M./Thyssen, C. (eds.), Corporate Values and Responsibility. Copenhagen: Samfundslitteratur, 145-154.

Morsing, M. 2006: Corporate social responsibility as strategic auto-communication: on the role of external stakeholders for member identification. In Business Ethics: A European Review 15(2), 171-182.

Morsing M./Beckmann, S.C. 2006: Strategic CSR Communication. Djøf Publishing.

Morsing, M./Schultz, M. 2006: Corporate social responsibility communication: stakeholder information, response and involvement strategies. In Business Ethics: A European Review 15(4), 323-338.

Morsing, M./Schultz M./Nielsen K.U. 2008: The Catch 22 of Integrating CSR and Strategic Marketing?

Murillo, D./Lozano, J.M. 2006: SMEs and CSR: An Approach to CSR in their Own Words. In Journal of Business Ethics. Special issue: Small and Medium-sized Enterprises \& Corporate Social Responsibility: Identifying the Knowledge Gaps 67(3).

Nielsen, A.E./Thomsen, C. 2007: What they say and how they say it. In Corporate Communications: An International Journal 12(1), 25-40.

Nielsen, A.E./Thomsen, C. 2009: Investigating CSR communication in SMEs: a case study among Danish middle managers. In Business Ethics: A European Review 18(1), 83-93.

O'Connor, A./Shumate, M. 2010: An Economic Industry and Institutional Level of Analysis of Corporate Social Responsibility Communication. In Management Communication Quarterly 24(4), 529-551.

O'Connor, M./Spangenberg, J.H. 2008: A methodology for CSR reporting: assuring a representative diversity of indicators across stakeholders, scales, sites and performance issues. In Journal of Cleaner Production 16(13), 1399-1415.

Parquel, B./Benoît-Moreau, F./Larceneau,x F. 2011: How Sustainability Ratings Might Deter “Greenwashing”: A Closer Look at Ethical Corporate Communication. In Journal of Business Ethics 102, 5-28.

Pedersen, E.R. 2006: Making Corporate Social Responsibility (CSR) Operable: How Companies Translate Stakeholder Dialogue into Practice. In Business \& Society Review 111(2), 137-163.

Podnar, K. 2008: Guest Editorial: Communicating Corporate Social Responsibility. In Journal of Marketing Communications 14(2), 75-81.

Pollach, I. 2003: Communicating Corporate Ethics on the World Wide Web - A Discourse Analysis of Selected Company Web Sites. In Business and Society 42(2), 277-287.

Pollach, I./Johansen, T./Nielsen, A.E./Thomsen, C. 2012: The Integration of CSR into Corporate Communication in Large European Companies. In Journal of Communication Management 16(2).

Porter, M.E./Kramer, M.R. 2006: Strategy and Society: The Link Between Competitive Advantage and Corporate Social Responsibility. In Harvard Business Review 84(12), 78-92.

Prahalad, C.K./Ramaswamy, V. 2004: The Future of Competition: Co-creating Unique Values with Customers. Harvard Business School Press.

Schlegelmilch, B.B./Pollach, I. 2005: The Perils and Opportunities at Communicating Corporate Ethics. In Journal of Marketing Management 21(3/4), 267-290.

Shaomin, L./Fetscherin, M./Alon, I./Lattemann, C./Kuang, Y. 2010: Corporate Social Responsibility in Emerging Markets. In Management International Review (MIR) 50(5), 635-654.

Smith, N.C./Palazzo, G./Bhattacharya, C.B. 2010: Marketing's Consequences: Stakeholder Marketing and Supply Chain Corporate Social Responsibility Issues. In Business Ethics Quarterly 20(4), 617-641.

Ströh, U. 2008: The conundrum of public relations versus marketing: Clarifying the differences in terms of relationship management. PRism [online]. http://www.prismjournal.org/fileadmin/Praxis/Files/Journal_Files/Stroh.pdf.

Sweeney, L./Coughlan, J. 2008: Do different industries report Corporate Social Responsibility differently? An investigation through the lens of stakeholder theory. In Journal of Marketing Communications 14(2), 113-124.

Taneja, S.S./Taneja, P.K./Gupta, R.K. 2011: Researches in Corporate Social Responsibility: A Review of Shifting Focus, Paradigms and Methodologies. In Journal of Business Ethics 101 (3), 343-364. 
Taneja, S.S./Taneja, P.K./Gupta, R.K. 2011: Researches in Corporate Social Responsibility: A Review of Shifting Focus, Paradigms, and Methodologies. In Journal of Business Ethics 101(3), 343-364.

Tang, L./Li, H. 2009: Corporate social responsibility communication of Chinese and global corporations in China. In Public Relations Review 35(3), 199-212.

Tewari, R. 2011: Communicating Corporate Social Responsibility in Annual Reports: A Comparative Study of Indian Companies \& Multi-National Corporations. In Journal of Management \& Public Policy 2(2), 22-51.

Tillmann, W./Lutz, R.J./Weitz, B.A. 2009: Corporate Hypocrisy: Overcoming the Threat of Inconsistent Corporate Social Responsibility Perception. In Journal of Marketing 73, 77-91.

Vanhamme, J./Grobben, B. 2009: Too Good to be True! The Effectiveness of CSR History in Countering Negative Publicity. In Journal of Business Ethics 85, 273-283.

van Riel, C.B.M. 1995: Principles of Corporate Communication. Prentice Hall, Harlow.

Wanderley, L./Lucian, R./Farache, F./Sousa Filho, J. 2008: CSR Information Disclosure on the Web: A Context-Based Approach to Analysing the Influence of Country of Origin and Industry Sector. In Journal of Business Ethics 82(2), 369-378.

Wang, J./Chaudhri, V. 2009: Corporate social responsibility engagement and communication by Chinese companies, In Public Relations Review 35, 247-50.

Yoon, Y./Gürhan-Canli, Z. 2004: The effect of corporate social responsibility (CSR) on product quality evaluations. In Advances in Consumer Research 31.

Ziek, P. 2009: Making sense of CSR communication. In Corporate Social Responsibility \& Environmental Management 16. 
